\title{
Millet cultivation $h$ istory in the French Alps as evidenced by a sedimentary molecule
}

Jérémy Jacob ${ }^{11}$, Jean-Robert Disnar ${ }^{1}$, Fabien Arnaud ${ }^{2}$, Emmanuel Chapron ${ }^{1}$, Maxime Debret ${ }^{2}$, Elisabeth Lallier-Vergès ${ }^{1}$, Marc Desmet ${ }^{2}$ and Marie Revel-Rolland ${ }^{3}$.

1. ISTO, UMR 6113 du CNRS/Université d'Orléans, Bâtiment Géosciences, 45067 Orléans, France.

2. EDYTEM, UMR 5204 du CNRS/Université de Savoie, Campus Savoie Technolac, F73376, le Bourget du Lac, France.

3. Geosciences Azur, UMR 6526 du CNRS, La Darse, B.P. 48, 06235 Villefranche sur mer, France.

\section{Abstract}

We report on the detection, in a sediment core drilled in Lake Le Bourget (French Alps), of a fossil molecule (miliacin) that was synthesized by broomcorn millet cultivated in the watershed, and then exported to the sediment. The variation in abundance of this molecule allows us reconstructing the history of millet cultivation around Lake Le Bourget. Our results support the introduction of millet around $-1700 \mathrm{BC}$ in the region. After an intensive cultivation during the Late Bronze Age, the failure of millet cropping during the Hallstatt period coincides with a phase of climatic deterioration. Millet cultivation recovers during the Roman and Mediaeval periods before falling most probably due to the introduction of more productive cereals. These pioneering results constitute the first continuous record of an agrarian activity for the last 6000 yrs and emphasize the close relationships between local hydrology, land use and agro-pastoral activities around Lake Le Bourget.

Keywords: Land use, agriculture, millet, Holocene, Bronze Age, molecular biomarker, lake sediments.

\footnotetext{
* Corre sponding author e-mail address : jeremy.jacob@univ-orleans.fr (J. Jacob)
} 


\section{Introduction}

Past relationships between human land-use and the earth/climate system are of direct relevance for predicting the response of continental ecosystems to a possible Global Change (Ruddiman, 2003; Dearing, 2006; Hurtt et al., 2006). High resolution sedimentary archives combined with more punctual archaeological investigations have proven useful in linking past human activities with environmental and climatic changes (Magny et al., 2004). Nevertheless, the absence of continuous records of agrarian practices due to the lack of pertinent tracers in sedimentary archives forbids the discrimination between human land-use and climatic impacts on continental ecosystems within a common time frame.

Lake Le Bourget (Figure 1) affords an exceptional context for studying such human/climate interactions. Previous studies showed that the terrigenous fraction deposited in this lake during Rhône River floods record the hydrological variability that affected the Alps during the Holocene (Chapron et al., 2002; 2005; Arnaud et al., 2005; Revel-Rolland et al., 2005). This lake also beneficiates from a rich archaeological context that consists mostly of Neolithic and Late Bronze Age settlements, but also of archaeological sites dated from the Iron Age, the Roman and the Middle Age periods (Marguet, 2002; Figure 1).

Fossil molecules produced by once-living organisms can be preserved in sedimentary archives and have proven useful in reconstructing past environments and biological communities (Meyers, 2003). Some of these molecules are produced by a narrow range of organisms. When found in sediments they allow certifying the former presence of their biological sources in the catchment. For example, the detection in tropical lacustrine sediments of pentacyclic triterpene methyl ethers (PTMEs) specific of gramineae offers the possibility to decipher the dynamics of various grasses through time (Jacob et al., 2005). We here reconstruct the history of millet cultivation in the catchment of Lake Le Bourget from the 
variation in concentration of a specific molecule (miliacin) detected in the sediments of this lake.

\section{Materials and methods}

Lake Le Bourget is a foreland lake located in front of the French NW Alps ( $45^{\circ} \mathrm{N} 45^{\prime}$; $5^{\circ} \mathrm{E} 52$ ', 231,5 $\mathrm{m}$ a.s.1., $18 \mathrm{~km}$ long, 2-3 $\mathrm{km}$ wide, $146 \mathrm{~m}$ deep). The catchment area is characterized by a local watershed of $600 \mathrm{~km}^{2}$ related to the Leysse and Sierroz rivers that expands up to $4000 \mathrm{~km}^{2}$ during sporadic major flooding events of the Rhône River through Lake Le Bourget outlet, the Savière canal (Figure 1).

Cores LDB04-I and LDB04-II (N 4547,140; E 550,440) were retrieved in 2004, at $106 \mathrm{~m}$ depth, with an UWITEC coring device operated from a barge. This coring site was selected on the basis of the seismic data(Chapron et al., 2005) at the entry of the Savière canal (Figure 1). The sediments deposited at this site are assumed to better record the flooding activity of the Rhône River into the lake than core LDB01 previously taken in a more distal depocenter (Chapron et al., 2005; Arnaud et al., 2005). A 14 m continuous composite series (LDB04) was established from two series of overlapped 3m-long cores according to sedimentological properties.

The age model was first established by using ten AMS ${ }^{14} \mathrm{C}$ radiocarbon dates performed at the Radiocarbon Laboratory in Poznan and at the Laboratoire de Mesure du Carbone 14 in Gif-sur-Yvette (Table 1). Four additional ${ }^{14} \mathrm{C}$ AMS dates from core LDB01 (Chapron et al., 2002; Arnaud et al., 2005) were integrated in the age model. Their stratigraphic position in core LDB01 was reported on core LDB04 by comparing the magnetic susceptibility and colour measurements performed at a $5 \mathrm{~mm}$ sampling step on both cores. Over the historical period a detailed dating was obtained using radiometric markers, the onset of lake eutrophication in 1948 and a series of thick flood deposits corresponding to historical 
catastrophic floods that occurred in years 1732-1734 (Table 2; Chapron et al., 2002). All calibrated ages were computed according to the 5.0.2 version of Intcal, using the calibration curve of Reimer et al., 2004). Samples between 583 and $698 \mathrm{~cm}$ depth correspond to a slump. The resulting age-depth relationsh ip is illustrated in Figure 2.

120 samples of $1 \mathrm{~cm}$ thickness covering the $2000 \mathrm{AD} /-4000 \mathrm{BC}$ time interval were selected for lipid analyses on the 7 first meters of core LDB04. The sampling interval is 10 $\mathrm{cm}$ over the core except for the 2-5 $\mathrm{m}$ section that beneficiated from a higher resolution (3-5 $\mathrm{cm}) .2 \mathrm{~g}$ of dried sediment were extracted three times with a mixture of dichloromethane:methanol $(1: 1 \mathrm{v} / \mathrm{v})$. After centrifugation, the supernatants were combined and dried under nitrogen before separation into acidic and neutral compounds according to Jacob et al. (2005). The neutral fraction was analysed by Gas Chromatography-Mass Spectrometry following the procedure modified from Jacob et al. (2005). Due to possible coelutions during GC separation, miliacin abundances were estimated by measuring the area of the miliacin peak on the $m / z 189+204+218$ ion specific chromatogram. $5 \alpha$-cholestane was used as an internal standard and miliacin (provided by Pr. R. Smith, Loughborough University, UK) was used as an external standard.

Bulk sedimentary titanium (Ti) was measured over the core at $1 \mathrm{~cm}$ spacing with a profiling XRF core scanner at the University of Bremen. Ti is given as counts per seconds (Figure 3c).

\section{Results and in terpretation}

Miliacin (olean-18-en-3 $\beta$-ol methyl ether; Figure 3a) is the sole PTME detected in the lipid extract of sediment samples selected on core LDB04. PTMEs are constituents of leaf waxes and are considered rather resistant to diagenesis, due to the supposed antifungal or antimicrobial role of pentacyclic triterpenes in waxes (e.g. Jacob et al., 2005). Hence, if other 
PTMEs were produced in significant amount in the catchment, they should be detected in our GC traces. Since this is not the case, miliacin was the only PTME produced in significant amounts on the lake surroundings. Despite their resistance, pentacyclic triterpenes are known to suffer minor structural rearrangements during diagen esis (ten Haven et al., 1992; Rullkötter et al., 1994). However, oleanane-type compounds owning a double bond at the $\Delta^{18}$ position (as miliacin) are the less thermodynamically stable isomers and are most likely to suffer rearrangements, such as double bond migration, into the more stable $\Delta^{13,18}$ or $\Delta^{12}$ isomers, whereas the reverse is unlikely. Therefore, miliacin cannot result from the diagenes is of other PTMEs with an oleanane structure.

Very few plants are known to produce miliacin as the sole PTME (Ohmoto et al., 1970; Jacob et al., 2005). They comprise Microstegium vimineum, Panicum miliaceum, P. dichotomiflorum, Syntherisma sanguinalis and Glyceria acutifolia. Archeaobotanical studies performed on a contemporaneous lake-shore settlement (Grésine, Figure 1) afforded a rather realistic panorama of the surrounding vegetation (Bouby and Billaud, 2001). The confrontation of the known exclusive miliacin producers with this regional inventory supports Panicum miliaceum (broomcorn millet) as the sole possible source of miliacin in the catchment. This introduced cereal was cultivated for staple food, as demonstrated by the numerous millet remains found at the Grésine archaeological site (Bouby and Billaud, 2001).

Although miliacin may be transported by runoff that affects soils formerly cultivated for millet, leaf waxes are predominantly ablated and wind transported on short distances with no time lag (e.g. Hughen et al., 2004). Therefore, miliacin detected in the sediments of Lake Le Bourget attests to the cultivation of millet in the vicinity of Lake Le Bourget, at the time of sediment deposition. 
The first occurrence of miliacin at ca. $1700 \mathrm{BC}$ (Figure 3b) is consistent with the supposed introduction of millet in the region (Marinval, 1995) during the Bronze Age. It extends down to $1700 \mathrm{BC}$ the previous estimation of intensive human impact on soils in the region (Chapron et al., 2005), although agrarian activities might have been constrained to the landscape surrounding the villages at that time (Bouby and Billaud, 2001). The drastic decrease in miliacin concentrations at ca. $800 \mathrm{BC}$ coincides with relatively high $\mathrm{Ti}$ values (Figure 3c) that attest to an increase in Rhône river floods into Lake Le Bourget. This corresponds to the regionally recorded climatic deterioration supposedly responsible for the abandonment of lake-dwelling habitats (Magny, 2004). The 500 BC/700 AD time interval shows higher concentrations of miliacin, in agreement with evidences of intensive agropastoral activity in the region (Chapron et al., 2005). The sudden decrease of miliacin concentrations at $700 \mathrm{AD}$ could illustrate the replacement of millet by other cereals or, alternatively, the failure of farming due to higher hydrological activity, as attested again by high Ti scores (Figure 3c). Then, low concentrations of miliacin reflect an input from the erosion of soils formerly cultivated for millet.

\section{Conclusion}

The detection of a sedimentary lipid specific of a cultivated plant provides the first continuous record of an agrarian activity in the catchment of Lake Le Bourget. By comparing this record with an index of hydrological variability in the region we show that periods of enhanced rainfall over the area affected the intensity of millet cropping. Because other plants of economic interest such as Oryza sativa (rice) or Sorghum bicolor (sorghum) synthesize molecules related to miliacin (Jacob et al., 2005), the detection of such compounds in timeconstrained continental archives will provide outstanding insights into the dynamics of agriculture history. 


\section{Acknowledgments}

This work is part of the APHRODYTE project, supported by the French CNRS (Programme ECLISPE 2005-2006). We thank J. Dearing for improving the manuscript and anonymous reviewers for their constructive comments.

\section{References}

Arnaud, F., Revel, M., Chapron, E., Desmet, M., Tribovillard, N., 2005. 7200 years of Rhône River flooding activity in Lake Le Bourget: a high-resolution sediment record of the NW Alps hydrology. Holocene 15, 420428.

Bouby, L., Billaud, Y., 2001. Economie agraire à la fin de l'âge du Bronze sur les bords du lac du Bourget (Savoie, France). Cr. Acad. Sci. II A 333, 749-756.

Chapron, E., Arnaud, F., Noël, H., Revel, M., Desmet, M., Perdereau, L., 2005. Rhône River flood deposits in Lake Le Bourget: a proxy for Holocene environmental changes in the NW Alps, France. Boreas 35, 404-415.

Chapron, E., Desmet, M., De Putter, T., Loutre, M.F., Beck, C., Deconninck, J.F., 2002. Climatic variability in the northwestern Alps, France, as evidenced by 600 years of terrigenous sedimentation in Lake Le Bourget. Holocene 12, 177-185.

Dearing, J., 2006. Climate-human-environment interactions: resolv ing our past. Clim. Past 2, 187-203.

Ten Haven, H.L., Peakman, T.M., Rulkötter, J., 1992. Early diagenetic transformation of higher-plant triterpenoids in deep-sea sediments from Baffin Bay. Geochim. Cosmochim. Acta 56, 2001-2024.

Hughen, K.A., Eglinton, T.I., Xu, L., Makou, M., 2004. Abrupt tropical vegetation response to rapid climate changes. Science 304, 1955-1959.

Hurtt, G.C., Frolking, S., Fearon, M.G., Moore III, B., Shevliakova, E., Malyshev, S., Pacala, S., Houghton, R.A., 2006. The underpinnings of land-use history: three centuries of global gridded land-use transitions, wood-harvest activity, and resulting second ary lands. Glob. Change Biol. 12, 1208-1229.

Jacob, J., Disnar, J.R., Boussafir, M., Sifeddine, A., Albuquerque, A.L.S., Turcq, B., 2005. Pentacyclic triterpene methyl ethers in recent lacustrine sediments (Lagoa do Caçó, Brazil). Org. Geochem. 36, 449-461.

Magny, M., 2004. Ho locene climate variability as reflected by mid-European lake-level fluctuations and its probable impact on prehistoric settlements. Quat. Int. 113, 65-79 (2004). 
Marguet, A., 2002. Savoie, lac du Bourget. Elaboration de la carte archéologique des gisements du lac du Bourget. In: Bilan Scientifique 2000 du DRASSM 26. Min istère de la Culture et de la Communication, Paris, p. 117-137.

Marinval, P., 1995. Données carpo logiques françaises sur les Millets (Panicum miliaceum L. et Setaria italica L. Beauv.) de la Protohistoire au Moyen Age. In: Hörandner, E. (Ed.) Millet. Actes du Congrès d’Aizenay (1990). Peter Lang, Frankfurt, p. 31-61.

Meyers, P.A., 2003. Applications of organic geochemis try to paleolimnological reconstructions: a summary of examples from the Laurentian Great Lakes. Org. Geochem. 34, 261-289.

Ohmoto, T., Ikuse, M., Natori, S., 1970. Triterpenoids of the Gramineae. Phytochem. 6, 2137-2148.

Reimer, P.J., Baillie, M.G.L., Bard, E., Bayliss, A., Beck, J.W., Bertrand, C., Blackwell, P.G., Buck, C.E., Burr, G., Cutler, K.B., Damon, P.E., Edwards, R.L., Fairbanks, R.G., Friedrich, M., Guilderson, T.P., Hughen, K.A., Kromer, B., McCormac, F.G., Manning, S.W., Ramsey, C.B., Reimer, R.W., Remmele, S., Southon, J.R., Stuiver, M., Talamo, S., Taylor, F.W., van der Plicht, J., Weyhenmeyer, C.E., 2004. IntCal04 terrestrial radiocarbon age calibration, 0-26 cal kyr BP. Radioc arbon 46, 1029-1058.

Revel-Rolland, M., Arnaud, F., Chapron, F., Desmet, M., Givelet, N., Alibert, C., McCulloch, M., 2005. Sr and $\mathrm{Nd}$ is otopes as tracers of clas tic sources in Lake Le Bourget sediment (NW Alps, France) during the Little Ice Age: Palaeohydrology implic ations. Chem. Geol. 224, 183-200.

Ruddiman, W.F., 2003. The anthropogenic greenhouse era began thousands of years ago. Climate Change 61, 261-29.

Rullkötter, J., Peakman, T.M., ten Haven, H.L., 2004. Early diagenesis of terrigenous triterpenoids and its implications for petroleum geochemistry. Org. Geochem. 21, 215-233. 


\section{Table captions}

Table 1: ${ }^{14} \mathrm{C}$ and non- $-{ }^{14} \mathrm{C}$ dates used for the establishment of core LDB04 age model.

\begin{tabular}{|c|c|c|c|c|c|c|c|c|}
\hline \multicolumn{9}{|c|}{ Non- $-{ }^{14} \mathrm{C}$ age information } \\
\hline \multicolumn{3}{|l|}{ His torical event } & \multicolumn{3}{|c|}{ Depth $(\mathrm{mm})$} & \multicolumn{2}{|c|}{ Age (yrs AD) } & $\begin{array}{l}\text { Age (yrs } \\
\text { cal. BP) }\end{array}$ \\
\hline \multicolumn{3}{|c|}{ Cher nobyl accident $\left({ }^{137} \mathrm{Cs}\right)$} & LDB04-I & \multicolumn{2}{|c|}{20} & \multicolumn{2}{|c|}{1986} & -36 \\
\hline \multicolumn{3}{|c|}{ Atmos pheric bomb tests $\left({ }^{137} \mathrm{Cs}\right.$ and $\left.{ }^{241} \mathrm{Am}\right)$} & LDB04-I & \multicolumn{2}{|c|}{50} & \multicolumn{2}{|c|}{1965} & -15 \\
\hline \multicolumn{3}{|l|}{ Eutrophication } & LDB04-I & \multicolumn{2}{|c|}{80} & \multicolumn{2}{|c|}{1948} & 2 \\
\hline \multirow{2}{*}{\multicolumn{3}{|c|}{ His torical flood }} & LDB04-I & \multicolumn{2}{|c|}{190} & \multicolumn{2}{|c|}{1888} & 62 \\
\hline & & & LDB04-I & \multicolumn{2}{|c|}{240} & \multicolumn{2}{|c|}{1888} & 62 \\
\hline \multicolumn{3}{|l|}{ His torical flood } & LDB04-I & \multicolumn{2}{|c|}{640} & \multicolumn{2}{|c|}{1734} & 216 \\
\hline \multicolumn{9}{|c|}{${ }^{14} \mathrm{C}$ age and calibration infor mation } \\
\hline Laboratory code & Core & $\begin{array}{l}\text { Depth } \\
(\mathrm{mm})\end{array}$ & $\begin{array}{l}\text { Correlated posi } \\
\text { on LDB04 I (m }\end{array}$ & & \multicolumn{2}{|c|}{${ }^{14} \mathrm{C}$ Age $+/-2 \sigma$} & \multicolumn{2}{|c|}{$\begin{array}{c}2 \sigma \text { mean cal Age } \\
\text { (cal. BP) }\end{array}$} \\
\hline Poz-13986 & LDB04-I & 1440 & - & & 435 & $+1-30$ & 495 & $+1-35$ \\
\hline Poz-710 & LDB01-I & 2710 & 3350 & & 1200 & +-30 & 1120 & $+\mid-110$ \\
\hline Poz-13983 & LDB04-I & 3100 & - & & 1665 & +-30 & 1570 & $+/-60$ \\
\hline Poz-718 & LDB01-I & 4070 & 3810 & & 1800 & +-45 & 1715 & $+\mid-145$ \\
\hline Poz-716 & LDB01-I & 4405 & 2505 & & 2250 & +-30 & 2245 & +-95 \\
\hline SacA4834 & LDB04-I & 4128 & - & & 2770 & +-30 & 2870 & $+/-80$ \\
\hline Poz-13984 & LDB04-I & 4480 & - & & 2815 & +-30 & 2920 & $+1-80$ \\
\hline Poz-13985 & LDB04-I & 4990 & - & & 3300 & +-30 & 3525 & $+1-65$ \\
\hline Poz-10562 & LDB04-I & 5810 & - & & 4160 & +-35 & 4160 & $+1-60$ \\
\hline Poz-14033 & LDB04-I & 6960 & - & & 4640 & +-35 & 5385 & $+/-85$ \\
\hline Poz-721 & LDB01-I & 7910 & 7500 & & 5310 & $+/-40$ & 6110 & $+\mid-160$ \\
\hline Poz-14032 & LDB04-I & 7770 & - & & 5870 & $+/-40$ & 6690 & +-70 \\
\hline Poz-10563 & LDB04-I & 8400 & - & & 6610 & +-40 & 7505 & +-45 \\
\hline Poz-13987 & LDB04-I & 9440 & - & & 8080 & $+/-40$ & 9015 & $+/ 235$ \\
\hline SacA4836 & LDB04-I & 10835 & - & & 8655 & +-45 & 9615 & $+1-85$ \\
\hline SacA4835 & LDB04-I & 9875 & - & & 8720 & $+/-50$ & 9695 & $+/ 145$ \\
\hline SacA4837 & LDB04-I & 11655 & - & & 9320 & +-35 & 10500 & +-100 \\
\hline Poz-10565 & LDB04-I & 12180 & - & & 9450 & +-50 & 10695 & $+1-85$ \\
\hline Poz-10566 & LDB04-I & 12940 & - & & 9490 & H- 50 & 10850 & $+/ 170$ \\
\hline
\end{tabular}




\section{Figure captions}

Figure 1: Location of Lake Le Bourget and coring sites. The grey arrow indicates the trajectory of Rhône river floods over the Chautagne swamp and the Savière canal. Numerous archaeological sites ranging from the Neolithic up to the Mediaeval Period have been studied around Lake Le Bourget (Marguet, 2002). The Grésine site, dated to the Late Bronze Age, afforded numerous botanical remains such as seeds of Panicum miliaceum (broomcorn millet).

Figure 2: Age-depth model for core LDB04 established from ${ }^{14} \mathrm{C}$ and non- ${ }^{14} \mathrm{C}$ dates listed in Table 1.

Figure 3: (a) Structure of miliacin (olean-18-en-3ß-ol ME). Miliacin is a pentacyclic triterpene (three terpene motifs arranged into five cycles) that bears a methyl ether group (-O$\mathrm{CH}_{3}$ ). Although pentacyclic are common in the plant kingdom, those with a methyl ether group are principally synthesised by grasses (Jacob et al., 2005). In the case of Lake Le Bourget, miliacin found in sediments attests to the crop growing of broomcorn millet in the catchment. (b) Evolution of miliacin relative abundance in $\mathrm{ng} / \mathrm{g}$ sediment. (b) Variations of titanium (Ti, in counts per second; cps). Titanium accounts for the occurrences of Rhône River floods in Lake Le Bourget. The sediment load carried to Lake Le Bourget during Rhône River floods is enriched in Ti as compared to the sediments normally deposited in Lake Le Bourget (Revel-Rolland et al., 2005). Higher Ti values hence attest to higher activity of the Rhône River due to higher precipitation over the Rhône catchment. 
Figure 1

Figure 1

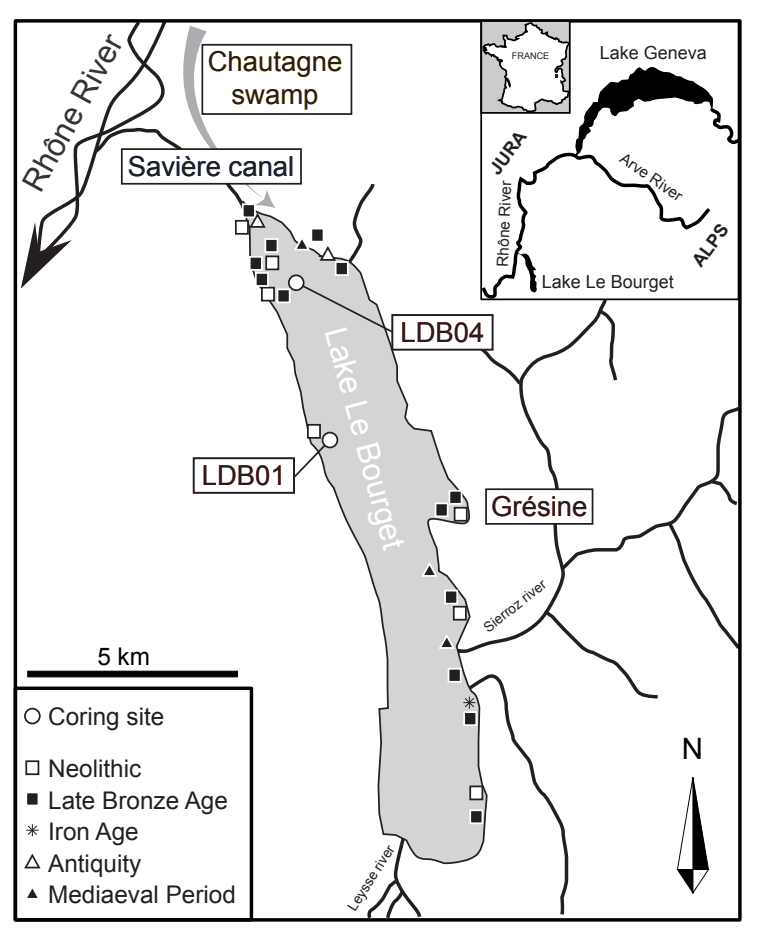


Figure 2

Figure 2

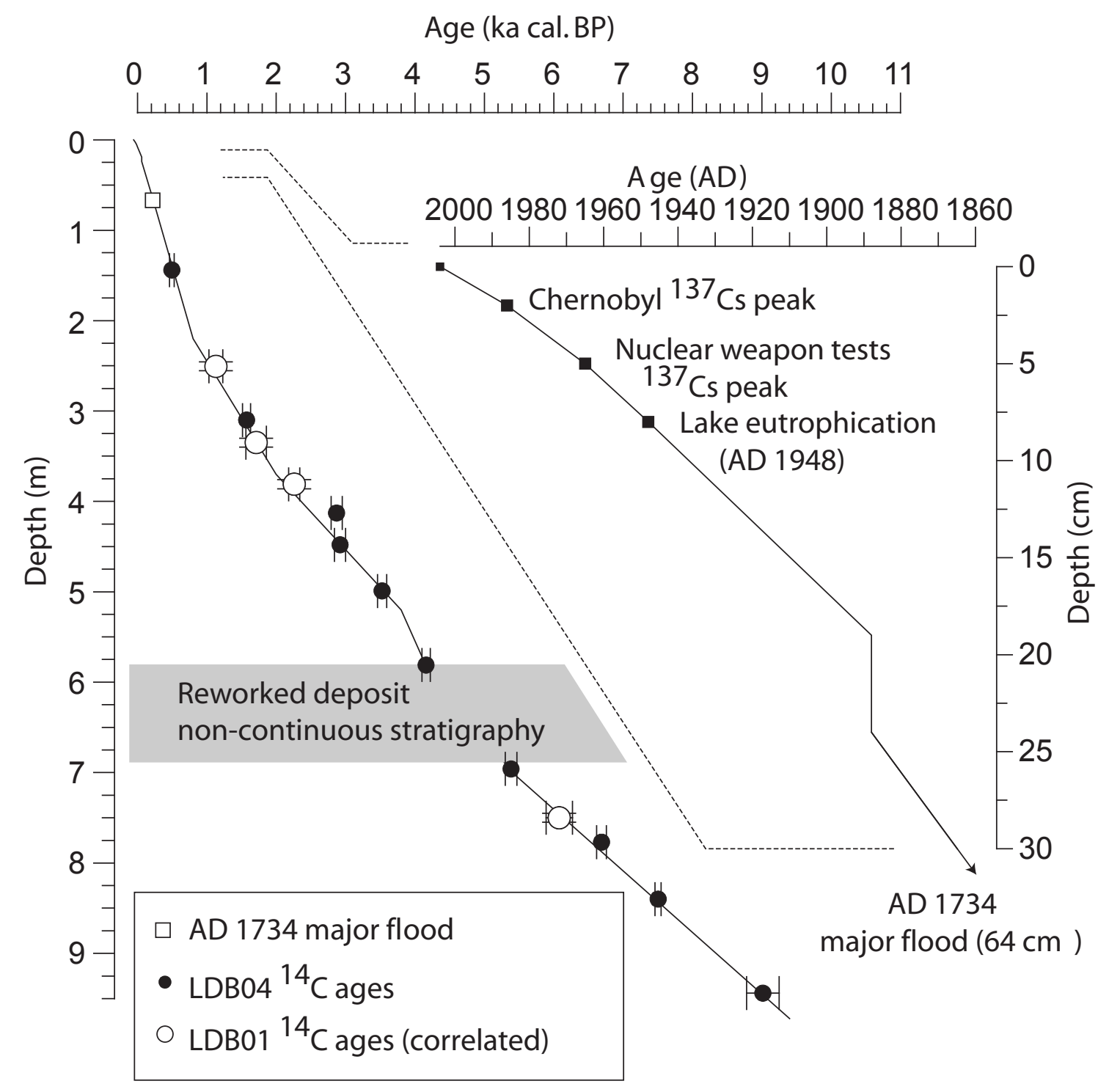


Figure 3

Figure 3

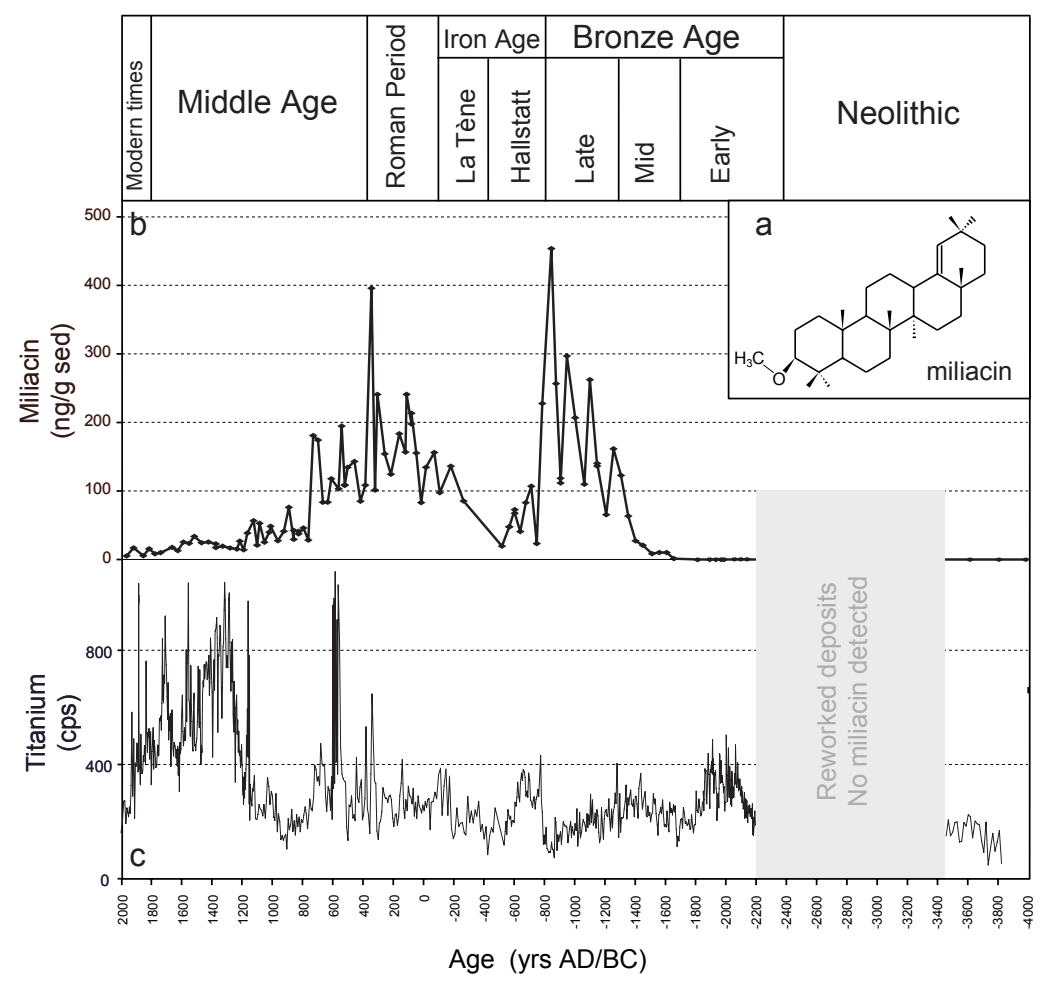

